\title{
ENSINO FUNDAMENTAL I: UM ENFOQUE CONSTRUTIVISTA DO MOVIMENTO SOBRE FORMAÇÃO ATITUDINAL
}

\author{
Marcelo Crepaldi Leitão \\ Universidade do Oeste Paulista, Presidente Prudente, São Paulo, Brasil \\ Yara Osorio \\ Universidade Gama Filho, Rio de Janeiro, Rio de Janeiro, Brasil
}

\begin{abstract}
Resumo
O objetivo deste estudo foi identificar as competências sociais desenvolvidas em um programa de Educação Física, no ensino fundamental I, com base na concepção construtivista de aprendizagem. O projeto foi longitudinal, com 20 escolares de ambos os sexos, entre nove e dez anos de idade. Os instrumentos de coleta de dados foram fichas protocolares validadas. As atividades desenvolvidas foram: jogos de construção e atividades baseadas em descoberta orientada e resoluções de problemas. Os procedimentos de análise foram qualiquantitativos. As variáveis estudadas apresentaram melhoras significativas. Os resultados indicaram que as atividades desenvolvidas na perspectiva construtivista foram eficazes na melhoria de capacidades relacionadas à autonomia e relações interpessoais.
\end{abstract}

Palavras chave: Desenvolvimento Infantil. Educação Física e Treinamento. Ensino.

\section{Introdução}

O fator determinante para a valorização de certas aprendizagens sobre outras, nos ambientes escolares, passa pela potencialidade de alcançar determinados objetivos propedêuticos a que a escola se propõe. Além dos conteúdos intelectuais, enfatizar o papel da escola na formação do cidadão influencia o viver no grupo social e no núcleo familiar, preparando o aluno para participar da sociedade de forma ativa e efetiva (NEIRA, 2003). De forma semelhante, Alves (2010) destaca que a assimilação de tais valores passa diretamente pelas experiências de relacionamento e colaboração, que, por sua vez, constroem noções de direitos e deveres. 
Tem sido demonstrada grande preocupação com omissões das instituições educativas em valorizar as práticas sociais entre os alunos, destacando-se que um dos problemas mais sérios enfrentados na formação do cidadão, é o "déficit de socialização", presente na sociedade atual. As instituições escolares não criam conteúdos que favoreçam o processo de socialização; ao contrário, é o conteúdo de socialização que define o desenho das instituições escolares. O ideal passa por uma escola que desenvolva mais trabalhos grupais em vez de competitivos, com destaque para a formação da personalidade do indivíduo, estimulando capacidades criativas, solidárias e afeitas à solução de problemas. A tendência das políticas educativas do futuro será fortalecer a educação básica, com atividades voltadas para a construção da autonomia dos alunos e a capacidade de estabelecer relações construtivas com seus pares, haja vista que somente uma boa educação básica permitirá desenvolver competências necessárias para a construção de uma capacidade produtiva cidadã (TEDESCO, 1998).

A democratização do saber deve revelar-se como objetivo fundamental da escola pública. É necessária a esta escola a seleção de conteúdos que permita aos alunos compreender a sua própria realidade e se fortalecerem como cidadãos, com a capacidade de transformá-la na direção do interesse coletivo. Os novos currículos já demonstram grande preocupação com relação ao ensino de atitudes e as introduzem atualmente como conteúdo educacional concreto. Não são valorizados somente os conteúdos procedimentais e conceituais, como tradicionalmente sempre foram, mas também a aprendizagem das atitudes, por intermédio da construção de valores (CORTELLA, 2000; SARABIA, 2000).

Vinha e Tognetta (2003) afirmam curiosamente que, pelo menos em teoria, nem sempre é explícita no projeto pedagógico das escolas a formação de pessoas obedientes, submissas e acríticas. Os educadores não possuem explicitamente esta intenção. O que se observa na prática é uma pedagogia voltada para a obediência cega às normas e regras, atuando de forma a promover mais a obediência em detrimento da autonomia e da reflexão. $\mathrm{Na}$ visão das autoras, se os valores morais não tiverem sido estruturados nos indivíduos por meio do exercício das inter-relações e da autonomia, eles apenas seguirão regras e princípios, mesmo na ausência de uma autoridade. No entanto, liberdade ou individualismo não constituem autonomia, que representa uma forma de tomar decisões, porém é preciso pensar nos anseios do grupo, respeitando equidade, diferenças, direitos e sentimentos. A pedagogia que pode promover uma formação virtuosa deve estar pautada nas relações sociais estabelecidas pela criança, com seus pares e com os adultos dentro da escola. Do ponto de vista do "intercâmbio de pensamentos, tal compreensão evolui à medida que se promovam as discussões" (TOGNETTA, 2007, p. 71).

A Educação Física, como parte importante do processo educacional, acompanha as discussões e tenta repensar formas de alcançar os objetivos finais da educação. De acordo com Sanches Neto e Betti (2008), o panorama atual, a 
partir dos anos 1980, identifica várias concepções, tais como abordagem humanista, desenvolvimentista, progressista, sistêmica, crítico-superadora, críticoemancipatória, estudos da saúde, estudos cinesiológicos e construtivistas. Como componente curricular, assume a tarefa de contribuir na formação de cidadãos autônomos e críticos, em que somente aprender a desenvolver capacidades e habilidade físicas não basta (BETTI; ZULLIANI, 2002). Como o construtivismo dá valor aos processos mentais e habilidades cognitivas, considerou-se essa ótica adequada para a construção da autonomia, entre outras qualidades.

Levando-se em conta as concepções dos autores citados, apresenta-se o objetivo deste estudo: analisar, entre escolares das séries finais do ensino fundamental I, o efeito de uma abordagem com enfoque construtivista sobre o comportamento de variáveis como a autonomia e as relações interpessoais.

Autores como Solé e Coll (1999), ao se referirem à concepção construtivista de aprendizagem, advogam que esta não antagoniza a construção individual do aluno à interação social. Existe a perspectiva de ensinar e aprender a construir o indivíduo inserido no grupo social. Não se trata apenas de um processo que busca o acúmulo de conhecimentos novos, "mas a integração, modificação, estabelecimento de relações e coordenação entre esquemas de conhecimento que varia, em vínculos e relações, a cada aprendizagem que realizamos" (SOLÉ; COLL, 1999, p. 20).

Ser um professor construtivista é não se basear apenas na transmissão de conteúdos, mas tratar a prática ou o ato pedagógico como uma investigação e experimentação. Ser construtivista exige a prática e a experimentação constantes no sentido de pesquisa e descoberta, de invenção, construção e de fazer melhor, buscando sempre a superação (MACEDO, 1994). Sarabia (2000, p. 139) destaca que o processo de aprendizagem baseado neste modelo e fundamentado na socialização deve ser contínuo "consciente ou inconsciente, voluntário ou involuntário, desejado ou simplesmente aceito - de atitudes ou de comportamentos", haja vista que cenários, personagens e normas, mudam constantemente. A socialização se define como uma aprendizagem realizada sempre em contextos interativos, e somente as mudanças atitudinais e comportamentais que ocorrem no processo de aprendizagem se enquadram nela, assim como tais mudanças advêm das interações estabelecidas entre os indivíduos, as quais se caracterizam como produtos da socialização.

Numa relação aproximada entre o pensamento de Sarabia (2000) e a Educação Física, Kamii e Devries (1991) destacam que os jogos de regras exercem grande influência na formação moral, social, cognitiva, emocional e política das crianças. Quando jogam em grupo, a atividade acontece somente se um consenso sobre as regras for estabelecido entre os jogadores. Korsakas e Rose Junior (2002) destacam que a pedagogia da autonomia deve se basear em práticas educativas que ofereçam aos alunos oportunidades de serem capazes de regular seus interesses individuais com independência e autodeterminação. 
Freire (2010), um dos autores mais representativos do Brasil no que se refere à abordagem da Educação Física escolar na perspectiva construtivista, ao longo de sua obra denominada Educação de corpo inteiro, valoriza significativamente as oportunidades que devem ser dadas ao aluno para o seu desenvolvimento individual, de forma integral e não fragmentada, e aponta o jogo como veículo facilitador no processo de construção da autonomia dos alunos. Quando se refere especificamente aos jogos de construção, sugeridos para serem trabalhados no período final da Educação Infantil e no início do Ensino Fundamental I, a partir da utilização de diferentes materiais e sucatas, analisa que estes favorecem um importante exercício na busca da autonomia operatória dos alunos (crianças mais autônomas em suas ações). Dessa forma, o professor deve se preocupar em dialogar com as crianças sobre as respectivas construções nesta fase. $O$ fato de a criança verbalizar suas ações irá contribuir para sua tomada de consciência. A evolução natural desse processo deverá se desencadear posteriormente numa forma mais elaborada de jogo, o jogo social, que consiste numa formação e organização marcada pela "atividade coletiva de intensificar trocas e a consideração pelas regras" (FREIRE, 2010, p. 63).

Duckur (2004), ao analisar as obras Educação de corpo inteiro, de João Batista Freire (1989), e o Coletivo de autores (SOARES et al., 1992) para o ensino de Educação Física, consideradas ainda propostas abertas e em construção, do ponto de vista do avanço dessas em relação à proposta tradicional (aptidão física), observa que estas indicam possibilidades para construções de práticas pedagógicas que objetivam a formação de um aluno crítico e autônomo e destaca que a proposta construtivista de Freire, mesmo com enfoque na Educação infantil e séries iniciais do Ensino fundamental I, pode ser desenvolvida também no ensino fundamental II e Ensino médio, destacando a importância da construção de uma cultura democrática em que os alunos aprendem a se organizar, discutir regras, refletir sobre pontos específicos do jogo e a buscar soluções coletivas.

A autora lança um relevante questionamento, demonstrando o desejo da necessidade de compreensão por parte dos professores, sobre a aplicabilidade de tais teorias nos espaços escolares, ao mesmo tempo em que faz um alerta sobre a complexidade do tema, entendendo que, embora apresentem certas lacunas, como toda concepção pedagógica, estas se diferenciam de enfoques tradicionais e diretivos: "afinal, como pensar o papel do professor diante dos desafios de uma prática pedagógica que anuncia a emancipação e a autonomia como fins a alcançar? (DUKUR, 2004, p. 41). A autora evidencia ainda o pensamento de Freire (1989), quando o autor salienta que torna-se necessário que os professores ultrapassem o campo dos discursos e busquem a efetivação das ações quando se tem a intenção da construção de uma prática democrática para a autonomia. Para a autora uma disciplina somente será significativa ao aluno se esta possibilitar-lhe o estabelecimento de nexos entre o conhecimento e a sua construção social." 
Os Parâmetros Curriculares Nacionais (PCN) destacam a necessidade de organizações grupais e o favorecimento das interrelações na busca da autonomia do aluno, escopo deste estudo (BRASIL, 1997).

O documento observa ainda que, em se tratando de alunos especificamente do $2^{\circ}$ ciclo, crianças entre 9 e 10 anos, é de se esperar que ajam com mais independência em suas tarefas diárias. No tocante à Educação Física, os alunos já podem compreender melhor as regras dos jogos e possuem maior autonomia para organizarem-se, sendo oportuno também, por parte dos professores, um aprofundamento sobre jogos, regras, esportes, lutas, entre outras atividades.

O contexto educacional pode ser, para muitas crianças, o espaço adequado e apropriado para a aprendizagem e vivência de atividades lúdicas significativas e diversificadas, em que, no emprego do jogo, por parte dos professores, importantes repercussões podem ser observadas no tocante ao comportamento das crianças, que se sentem motivadas, inclusive para frequentar a Instituição. Tais práticas proporcionam evolução de comportamentos, tais como cooperação, respeito mútuo, troca de pontos de vista, desenvolvimento da autonomia, confiança em si mesmas, curiosidade e disposição para outras aprendizagens (LIMA, 2008).

Torna-se necessário repensar o fazer pedagógico dos professores de Educação Física atuantes em espaços escolares, atualmente, observando que o ato pedagógico em Educação Física deve ter intencionalidade e diretividade, do ponto de vista dos saberes que a criança deve adquirir (MARTINELI, 2004).

No tocante à regência de atividades que corroboram a concepção construtivista, Palma (2001) valoriza a formação continuada de professores numa perspectiva que supere a formação tradicional, para que o docente possa desenvolvê-la junto aos alunos, com mais propriedade em suas aulas. Para tanto, sugere a concepção construtivista de aprendizagem, alegando que esta se dá a partir da necessidade, do conflito, da inquietação e da falta de algo que o indivíduo possa sentir. Desse modo, consiste em mobilizar constantemente o professor para que este aja de forma ativa e possa construir conhecimentos a partir de coordenações e abstrações de suas ações.

Entende-se que, quando o processo de formação continuada se fundamentar nos pressupostos da corrente construtivista, ele possibilitará ao professor apresentar estruturas conceituais necessárias a um trabalho docente, que além de consciente, demonstrando competências profissionais, tanto práticas quanto teóricas, estará comprometido com a construção da cidadania dos seus alunos, como cidadãos críticos, ativos e autônomos (PALMA, 2001, p. 4).

Sobre a atuação do professor de Educação Física escolar, observa a autora que, quando a perspectiva construtivista passa a nortear o pensamento dos professores, a Educação Física passa a adquirir o "status de área de conhecimentos 
como componente curricular em uma escola" (PALMA, 2001, p. 92-93). Desse modo, a Educação Física passa a ter como objetivo, nesta concepção, a promoção de situações que irão permitir aos alunos socializar pensamentos e compreender um determinado conteúdo relacionado à motricidade, bem como o entendimento de seu significado e aquilo que ainda pode ser construído.

\section{Métodos}

\section{Preceitos éticos}

O projeto de pesquisa e o termo de consentimento livre e esclarecido foram aprovados pelo Comitê de Ética em Pesquisa da Rede Euroamericana de Motricidade Humana (protocolo 013/2009). A instituição escolar, os alunos e seus respectivos responsáveis foram informados sobre os objetivos deste estudo. Houve anuência da instituição escolar, assim como assinatura do termo de consentimento pelos pais e responsáveis pelos alunos.

Delineamento do estudo e amostra

O presente estudo constitui a finalização de um projeto de pesquisa longitudinal, que envolveu intervenção em meio escolar e teve algumas informações provenientes de seu estudo piloto publicados previamente por Leitão et al. (2011). Apresenta-se como pesquisa de metodologia mista, qualiquantitativa, que, para Lankshear e Knobel (2008), pode ser utilizada quando o problema permite múltipla abordagem.

A amostra foi constituída por 20 escolares de ambos os sexos com idade variando de oito a 10 anos e matriculados em uma escola pública da cidade de Presidente Prudente, região oeste do Estado de São Paulo, que não envolveu a totalidade da série cursada, apenas a turma disponível. Para Patton (1990 apud FLICK, 2007, p. 83), esse critério é denominado amostra de conveniência, que faz referência "à seleção daqueles casos mais fáceis de serem acessados em determinadas condições".

A faixa etária foi escolhida em função de algumas características relacionadas a esta idade, tais como estar inserida no estágio intermediário do período de desenvolvimento cognitivo correspondente ao operatório-concreto, na teoria construtivista (PIAGET, 1989) e corresponder ao período que compreende a fase entre a heteronomia e a autonomia, com relação ao desenvolvimento da moralidade (PIAGET, 1977). No início do estudo, os escolares envolvidos estavam cursando a terceira série do ensino fundamental I e, ao final, a quarta série.

Considerando todos os momentos da pesquisa entre intervenções e avaliações, o presente estudo teve uma duração de 26 semanas, ou seis meses, com frequência de dois encontros semanais de cinquenta minutos cada. As avaliações fo- 
ram realizadas mensalmente e registradas como Período $1(\mathrm{P} 1)$, Período $2(\mathrm{P} 2)$ e assim sucessivamente até o Período 6 (P6). O foco em cada período foi voltado para avaliação.

\section{Instrumentos de coleta de dados}

O instrumento de coleta de dados foi representado por seis fichas de observação utilizadas em cada período e pelo diário de campo. As fichas foram validadas por três doutores e aprovadas pelo comitê de ética em pesquisa. A ficha 1 registrou o desempenho individual em relação aos aspectos positivos frente às fases da aula, considerando as categorias autonomia e relações interpessoais. Para autonomia, foram avaliados: a) organização individual, b) respeito e obediência às regras com entendimento de seus benefícios, c) conscientização da necessidade de trabalhar em equipe, d) Independência e desprendimento na realização das tarefas. Para relações interpessoais, foram avaliados: a) respeito mútuo, b) companheirismo e solidariedade, e c) relacionamento com os colegas (inter-relações), durante a aplicação da pesquisa.

A ficha 2 envolveu aspectos negativos baseados na categoria atitudes egocêntricas e indiferentes, observando reações frente ao interesse nas atividades, subestimação e desprezo pelos colegas, indiferença em relação às necessidades dos companheiros.

A ficha 3 conteve relatos sobre cada aluno, descrevendo situações e atitudes individuais positivas ou negativas. A ficha 4 foi composta por relatos e observações de atitudes coletivas observadas durante as aulas ministradas. A ficha 5 registrou a sondagem sobre as atividades corporais realizadas pelo aluno fora do ambiente escolar. A ficha 6 registrou uma análise e acompanhamento dos possíveis progressos detectados em expressões escritas, verbalizadas e desenhadas.

Em estudo anteriormente realizado por Leitão et al. (2011), a autonomia e as relações interpessoais das crianças estudadas foram avaliadas nos seis momentos descritos acima (P1 a P6). Em cada um destes momentos, alguns critérios específicos de observação foram elaborados como instrumento de avaliação e, assim, foram atribuídos escores de acordo com o comportamento individual de cada aluno $(1=$ insatisfatório $[\mathrm{I}] ; 2=$ parcialmente satisfatório $[\mathrm{PS}] ; 3=$ satisfatório $[\mathrm{S}]$; 4= inteiramente satisfatório [IS]). Nesse sentido, maiores escores indicaram "melhor" desempenho nas características analisadas. Todas as observações, intervenções e avaliações foram registradas em diário de campo.

\section{Intervenção}

A intervenção ocorreu durante as aulas de Educação Física na quadra, em espaço aberto, regidas pelos fatores movimento, ludicidade, organização e resolução de problemas. Os jogos e atividades lúdicas programadas aconteceram duas 
vezes por semana, com sessões de 50 minutos de duração, compatíveis com a realidade das escolas públicas no Estado de São Paulo. Durante a intervenção, visando maior fixação do conteúdo trabalhado, os alunos participaram do programa de aulas e fizeram registros após cada encontro, além de, em algumas oportunidades, elaborar os registros como tarefas escolares a serem apresentadas nas aulas subsequentes.

As atividades desenvolvidas foram: realização de jogos de construção com e sem materiais, atividades baseadas em descoberta orientada, jogos de modificações e construções de regras em grupos, jogos de resoluções de problemas, elaboração de propostas e discussões de regras com o objetivo de construir, levando-se em consideração a posição do grupo, atividades inéditas. Essas atividades foram modificadas em grau de complexidade, em virtude do processo natural de assimilação e adaptação por parte dos alunos.

Tratamento estatístico

Em decorrência das características não paramétricas do conjunto de dados analisado, baseados em categorias, a comparação dos escores entre os seis momentos de análise foi conduzida utilizando-se o teste de Friedman. Quando houve diferença significativa, o teste de Wilcoxon indicou entre quais momentos houve esta diferença (post hoc). O nível de significância adotado em todas as análises foi de $\mathrm{p}<0,05$ (CONOVER, 1980).

\section{Resultados e discussão}

A Figura 1 (Painéis A e B) apresenta os box-plots (linha central: mediana; linha superior: valor do percentil 75; linha inferior: valor do percentil 25) dos períodos de P1 a P6 para as variáveis autonomia (Painel A) e relações interpessoais (Painel B). 
A

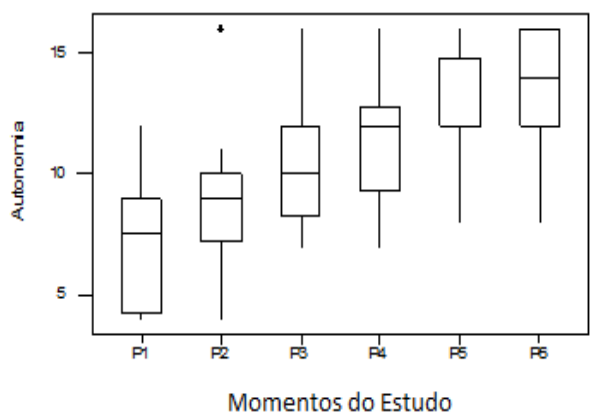

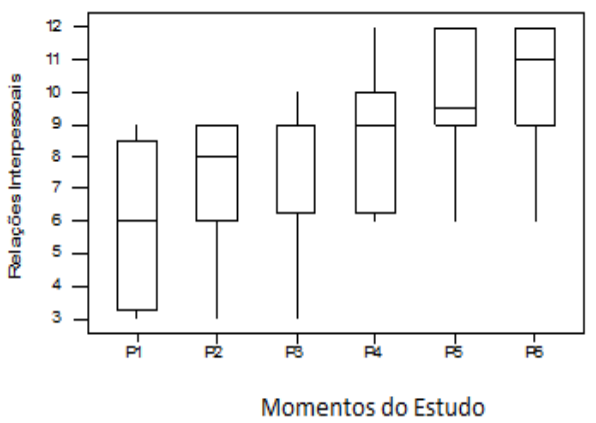

Figura 1. Apresentação gráfica dos períodos P1 a P6 para a variável autonomia (Painel A) e relações interpessoais (Painel B).

Foi possível evidenciar que houve aumento no escore ao longo de toda a intervenção. Leitão et al. (2011) indicaram que uma intervenção com duração de quatro meses já consegue influenciar ambas as variáveis. Os resultados complementam tal achado, uma vez que indicam que existe um efeito acumulativo, no qual quanto maior o tempo de intervenção, maior foi o escore nos atributos avaliados.

Em relação às experiências vivenciadas pelos alunos durante a pesquisa, podemos observar o valor que Piaget (1977) atribui à solidariedade e ao respeito mútuo, para que as crianças encontrem, em suas relações entre pares, o sentido de justo e injusto. $\mathrm{O}$ valor da experiência está implícito e aparece como condição essencial para internalização desses valores morais, ou seja, as vivências práticas, a interação afetiva, o exercício de observação de diferentes opiniões e a reflexão sobre regras, do ponto de vista do bem geral, podem ser mais efetivos do que os discursos e exemplos práticos dos adultos.

Foi possível constatar o valor da vivência, comparando a abordagem inicial dos alunos com a finalização do processo da pesquisa. No início, as crianças demonstraram bastante entusiasmo, porém aparentemente desorganizados diante das atividades propostas, que eram diferentes das experiências habituais no universo escolar.

Em face às colocações feitas, demonstraram interesse em se organizar, mas, de maneira geral, estiveram muito distantes de noções de regras e organização de atividades. No tocante à realização das tarefas propostas, entraram, diversas vezes de forma natural, em conflitos uns com os outros, porém tentaram se organizar. Alguns fizeram com mais sucesso, e outros ainda demonstraram dependência de comando e falta de criatividade.

À medida que as aulas iam acontecendo e situações novas eram vivenciadas, os alunos começaram a perceber a importância das regras na organização das atividades. Percebia-se um envolvimento maior por parte de alguns que eram le- 
vados pelas propostas lúdicas e menor interesse por parte de outros que encontravam dificuldades em se organizar e, ao mesmo tempo, respeitar regras que fossem interessantes a todos os participantes. $\mathrm{Na}$ organização dos primeiros jogos, apesar de a maioria demonstrar envolvimento, surgiram várias quebras de regras, conflitos interpessoais e diversos interesses individuais que se sobrepunham aos coletivos.

Apesar dos conflitos naturais que aconteceram a cada aula, as participações positivas existiam em maior proporção. Foi observado que nos jogos competitivos, com a socialização de algumas regras sugeridas pelos alunos, as condutas começaram a ser mais bem aceitas, pois favoreciam a maioria. $\mathrm{O}$ entendimento começou a ser incorporado. Por diversas vezes, foram observadas participações mais amistosas, maiores iniciativas individuais e coletivas nas tarefas propostas e condutas operatórias mais objetivas.

Com o decorrer do trabalho, as estratégias propostas e registradas para os novos jogos competitivos apresentados, onde todos poderiam opinar sobre modificações necessárias, começaram a se tornar mais eficazes do ponto de vista operacional, objetivo e, sobretudo, social afetivo.

Para a variável autonomia (Figura 2), o teste de Friedman indicou que houve diferenças significativas entre os momentos analisados $(\mathrm{p}=0,001)$. Por fim, o teste pareado de Wilcoxon foi aplicado e evidenciou que esta diferença significativa $(\mathrm{p}<0,05)$ ocorreu desde o segundo momento de análise $(\mathrm{P} 2)$. Nesse sentido, os aumentos observados nos períodos P5 e P6 são significativamente superiores aos observados no momento P4. Confirmando, assim, o efeito adicional acima citado. 


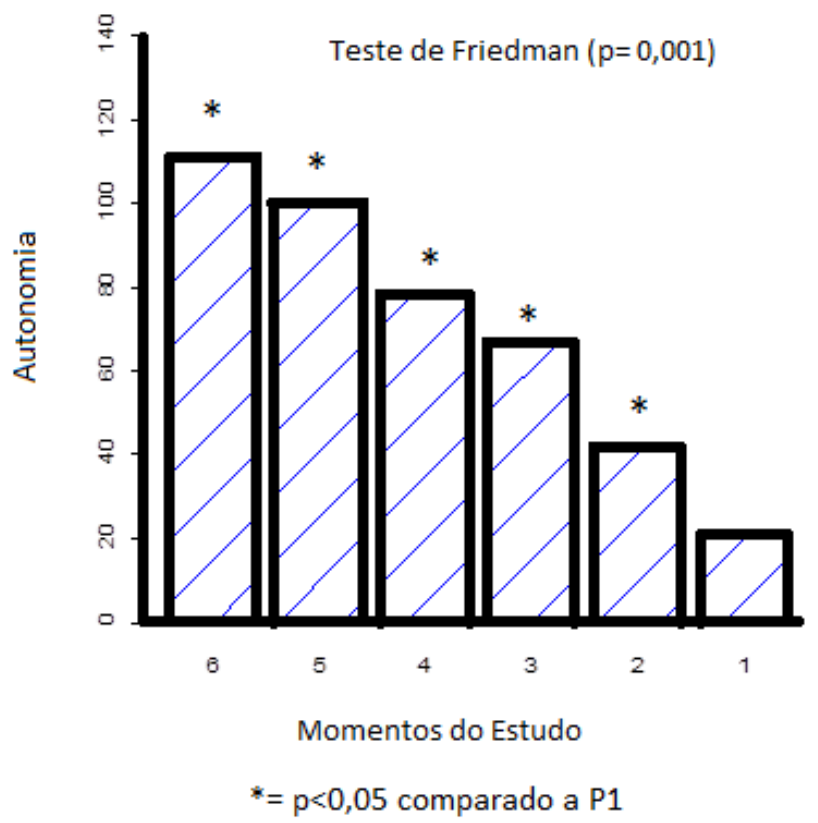

Figura 2. Somatória dos postos (ranks) para o escore de autonomia de acordo com os períodos 1 a 6 .

Para as relações interpessoais, houve diferença significativa entre os períodos analisados (Teste de Friedman com $\mathrm{p}=0,001$ [Figura 3]). Porém, ao adotar o momento inicial como referência, diferentemente do que ocorreu para autonomia, o teste de Wilcoxon indicou que houve diferença significativa $(p<0,05)$ apenas a partir do momento P3.

No caso das relações interpessoais, houve evolução da pontuação, avançando de 77,5 pontos em P4 (período estudado anteriormente) para 100,5 pontos em P5 e para 109 pontos em P6. Foi possível observar que houve uma evolução da pontuação nos períodos P5 e P6. Portanto, houve diferenças evolutivas nos quesitos autonomia e relações interpessoais, que excederam os quatro meses, como identificado por Leitão et al. (2011). 


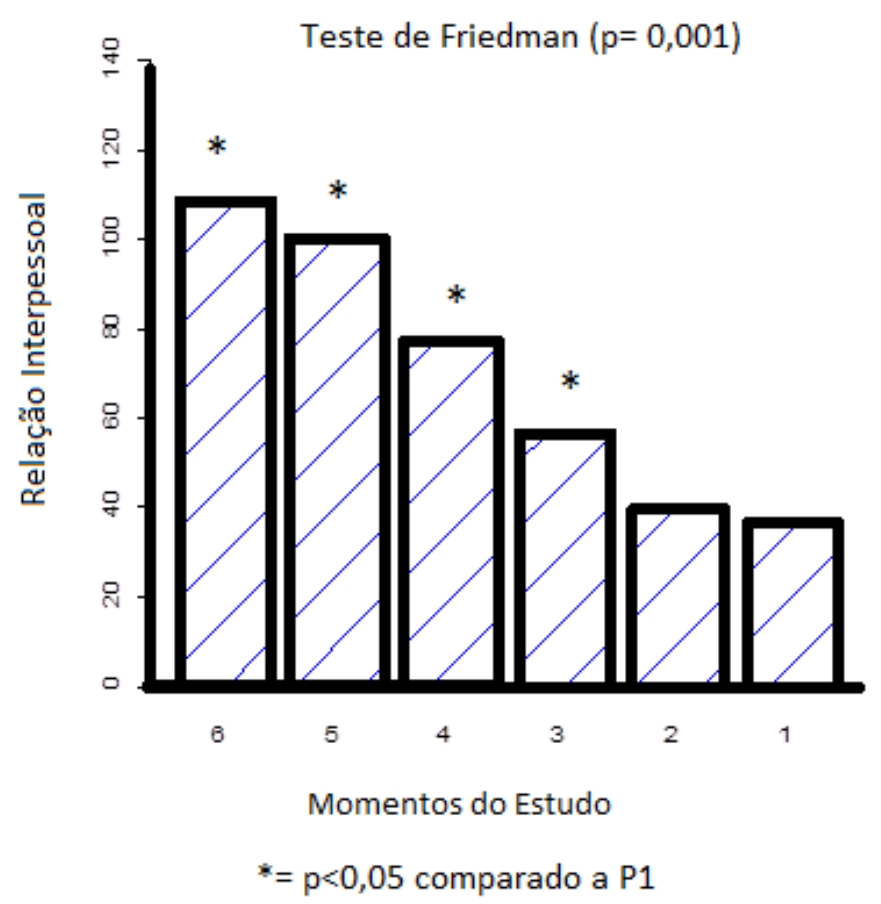

Figura 3. Somatória dos postos (ranks) para o escore de relação interpessoal de acordo com os períodos 1 a 6 .

Neste mesmo sentido, fazendo uma alusão às práticas educacionais, Macedo (1994) destaca que as regras devem sempre ser atualizadas e que, enquanto construídas, demandam consentimento, ao contrário das leis, que, por serem de natureza heterorreguladoras, exigem sempre a presença de uma autoridade que irá arbitrar os mandamentos estabelecidos. O autor reforça a ideia de um exercício constante de construção de regras em ambiente escolar, quando enfatiza que regras estabelecidas em consenso são autorreguladoras, por isso não necessitam de árbitros ou fiscais. Estes são os próprios participantes, por exemplo, numa situação de jogo.

Os PCN (BRASIL, 1997), quando se referem à problematização de regras como sugestões nas práticas efetuadas em Educação Física escolar, com crianças entre 8 a 10 anos, preconizam que os alunos discutam regras, tentando encontrar soluções e propostas de modificações que sejam estabelecidas em grupo. A compreensão pode originar-se naturalmente dessas atitudes, diferentemente daquelas que possuem regras absolutas e imutáveis. Estas práticas exercitam a melhoria das relações sociais e contribuem para a construção da autonomia dos alunos.

Nesta mesma visão, Menin (1985, p. 202) também enfatiza que,

Se a criança vive relações de respeito mútuo, busca, por pura necessidade de manter esta relação - ser respeitado e respeitar, obedecer a 
leis que conservem este convívio. Só nesta situação há, então, condição de autonomia - o homem obedece uma lei, a uma disciplina que por si próprio elege.

A autora afirma também que, se o processo educativo se limita à tendência heterônoma, onde estão presentes normas exteriores que obrigam todas as crianças, não haverá lugar para que eles ajam por consciência própria, autonomamente. Ela valoriza a prática das atividades grupais e destaca que a prática da cooperação torna-se importante para o andamento das atividades e para a aquisição da autonomia. No sentido moral, autonomia significa ser capaz de decidir de forma racional e entender uma regra como necessária para si e para os outros, ou seja, pensar no benefício coletivo e não somente de forma individual (MENIN, 1996). Ainda para a autora (2002), educar para a autonomia, baseado na moral piagetiana de uma educação voltada para a autonomia de indivíduos e adoção consciente e consentida de valores, não pode se realizar por meio de coação. Formar alunos que reflitam sobre valores existentes, capazes de optar por valores que tornam a vida social mais justa e feliz, numa visão coletiva, e ainda formar alunos críticos no tocante aos contravalores existentes torna necessária a participação da escola, criando situações em que essas atitudes sejam socializadas.

Isto reflete a teoria de Piaget (1996) quando destaca seu ponto de vista sobre a construção da autonomia moral, observando que, para que as realidades morais sejam constituídas, estas necessitam de uma disciplina normativa e, para que essa disciplina seja constituída, torna-se necessário que os indivíduos estabeleçam relações uns com os outros. Essas relações entre crianças e adultos ou crianças e seus pares poderão levá-las a adquirir a consciência do dever e a colocar acima de suas intenções essa realidade normativa em que consiste a moral. As inter-relações para a construção da autonomia moral da criança e, consequentemente, a aquisição da consciência sobre o justo e o injusto e esta construção moral devem ser permeadas por ações porque "não há, portanto, moral sem sua educação moral, educação no sentido amplo do termo, que se sobrepõe à constituição inata do indivíduo" (PIAGET, 1996, p. 3). A livre cooperação entre crianças conduz a resultados diferentes daqueles obtidos por intermédio da pressão dos adultos. $\mathrm{O}$ respeito mútuo nasce naturalmente das relações de cooperação e não de coação, e a moral que resulta do respeito mútuo e das relações cooperativas pode desenvolver na criança um sentimento do bem, mais anterior à consciência. Assim, a reciprocidade tende a tornar-se inteiramente autônoma.

\section{Considerações finais}

Os resultados apresentados nos permitem concluir que uma ação educacional, ajustada nos moldes da educação básica brasileira atual de duas aulas por semana, foi eficaz na melhoria de capacidades relacionadas à autonomia e rela- 
ções interpessoais. Além disso, conclui-se que quanto maior o tempo de exposição a ações educacionais deste tipo, maior parece ser o ganho que os escolares podem obter. Identificamos que a fundamentação teórica baseada na concepção pedagógica utilizada na construção deste estudo, bem como os instrumentos de avaliação dos escolares, foi determinante para uma reflexão docente sobre os aspectos positivos advindos destas práticas, do ponto de vista da formação social, haja vista que os resultados finais também foram significativos. Há necessidade de os espaços escolares refletirem sobre esta questão, pois determinadas intervenções podem apresentar consequências significativas na construção dos valores e regras que contemplam a formação moral de crianças e jovens.

\title{
ELEMENTARY SCHOOL: A CONSTRUCTIVIST APPROACH OF THE MOVEMENT ON THE FORMATION OF VALUES
}

\begin{abstract}
The purpose of this study was to identify the social implications through the development of a Physical Education program in the elementary teaching I level, according to the constructivist approach of learning. The project has been longitudinal with a sample of twenty male and female students aged from nine to ten years old. The collecting data method has been based on validated chips protocol. The activities developed have been established as follow: construction games with and actions based on directed discoveries and resolution of problems. The procedures of analysis have been done quanti and qualitativelly. All the possibilities studied have presented meaningful improvement. The results of this research have indicated that the activities developed by the constructivist method were effective regarding the progress of capabilities related to the autonomy and interpersonal relationship of the students.
\end{abstract}

Keywords: Child Development. Physical Education and Training. Teaching.

\section{ESCUELA PRIMARIA: UN ENFOQUE CONSTRUCTIVISTA DEL MOVIMIEN- TO EN LA FORMACIÓN DE VALORES}

\section{Resumen}

El objetivo de este estudio fue identificar las habilidades sociales mediante el desarrollo de un programa de Educación Física en la educación primaria, basado en la concepción constructivista del aprendizaje. El proyecto fue longitudinal, con una muestra de veinte estudiantes de ambos sexos, con edades comprendidas entre nueve y diez años. Los instrumentos de las formas de recogida de datos fueron validados fichas de protocolo. Las actividades fueron: realización de juegos de construcción y actividades basadas en el des cubrimiento orientado y resolución de problemas. Los procedimientos de análisis fueron cuali cuantitativos. Las variables estudiadas mostraron mejoras significativas. Los resultados indicaron que las actividades en la perspectiva constructivista son eficaces en la mejora de las habilidades relacionadas con la autonomía y las relaciones interpersonales.

Palabras-claves: Desarrollo Infantil. Educación y Entrenamiento Físico. Enseñanza. 


\section{Referências}

ALVES, R. A escola com que sempre sonhei sem imaginar que pudesse existir. Campinas: Papirus, 2010.

BETTI, M.; ZULLIANI, L. R. Educação Física Escolar: uma proposta de diretrizes pedagógicas. Revista Mackenzie de Educação Física e Esporte, São Paulo, v. 1, n.1, p73-81, 2002.

BRASIL. Secretaria de Educação Fundamental. Parâmetros Curriculares Nacionais: Educação Física / Secretaria de Educação Fundamental. Brasília: MEC/SEF, 1997.

CONOVER, W. J. Practical nonparametric statistics. 2. ed. New York: John Wiley and Sons, 1980.

CORTELlA, M. S. A Escola e o conhecimento: fundamentos epistemológicos e políticos. São Paulo: Cortez, 2000.

DUCKUR, L. C. B. Em busca da formação de indivíduos autônomos nas aulas de Educação física. Campinas: Autores Associados, 2004.

FLICK, U. Uma introdução à pesquisa qualitativa. 2. ed. Porto Alegre: Bookman, 2007.

FREIRE, João B. Educação de corpo inteiro. São Paulo: Scipione, 2010. . São Paulo: Scipione, 1989.

KAMII, C.; DEVRIES, R. Jogos em grupo na educação infantil: implicações da teoria de Piaget. São Paulo: Trajetória Cultural, 1991.

KORSAKAS, P.; ROSE JUNIOR, D. de. Os encontros e desencontros entre esporte e Educação: uma discussão filosófico-pedagógica. Revista Mackenzie de Educação, São Paulo, v. 1, n. 1, p. 83-93, 2002.

LANKSHEAR, C.; KNOBEL, M. Pesquisa pedagógica do projeto à implementação. Porto Alegre: Artmed, 2008.

LEITÃO, M. C. et al. Implicações Sociais e Autonomia em Educação Física escolar: uma abordagem construtivista do movimento. Revista Brasileira de Ciência e Movimento, Taguatinga, v. 19, n. 3, p. 76-85, 2011. 
LIMA, J. M. de. O jogo como recurso pedagógico contexto educacional. São Paulo: Unesp, 2008.

MACEDO, L. de. Ensaios construtivistas. São Paulo: Casa do Psicólogo, 1994.

MARTINELI, T. A. P. A prática reflexiva em ação: jogos e brincadeiras na Educação Física Escolar. In: VIEIRA, J. L. (Org.). Educação Física e Esportes: estudos e proposições. Maringá: Eduem, 2004. p. 129-153.

MENIN, M. S. de S. Autonomia e Heteronomia às regras escolares - observações e entrevistas na escola. 1985. 215 f. Dissertação (Mestrado em Psicologia Escolar e do Desenvolvimento Humano)-Instituto de Psicologia, Universidade de São Paulo, São Paulo, 1985.

. Desenvolvimento moral: refletindo com pais e professores. In: PIAGET, J. et al. (Orgs.). Cinco estudos de Educação moral. São Paulo: Casa do Psicólogo, 1996. p. 37-104.

. Valores na escola. Educação e Pesquisa, São Paulo, v. 28, n. 1, p. 91100, jan./jun. 2002.

NEIRA, M. G. Educação Física: desenvolvendo competências. Guarulhos: Phorte, 2003.

PALMA, A. P. T. V. A Educação física e o construtivismo: a busca de um caminho na formação continuada de professores. 2001. 138 f. Tese (Doutorado em Educação)-Faculdade de Educação, Universidade Estadual de Campinas, Campinas, 2001.

PIAGET, Jean. O julgamento moral da criança. São Paulo: Mestre Jou, 1977.

. Seis estudos de psicologia. 3. ed. Rio de Janeiro: Forense, 1989.

. Os procedimentos da Educação moral. In: PIAGET, J. et al. (Orgs.). Cinco estudos de Educação moral. São Paulo: Casa do Psicólogo, 1996. p.1-36.

SANCHES NETO, L.; BETTI, M. Convergência e integração: uma proposta para a Educação Física de $5^{\mathrm{a}}$ a $8^{\mathrm{a}}$ série do ensino fundamental. Revista Brasileira de Educação Física e Esporte, São Paulo, v. 22, n. 1, p. 5-23, jan./mar. 2008. 
SARABIA, B. A aprendizagem e o ensino das atitudes. In: COLL, C. et al. Os conteúdos da reforma: ensino e aprendizagem de conceitos, procedimentos e atitudes. Porto Alegre: Artes Médicas, 2000. p. 119-176.

SOARES, C. L. et al. Metodologia do Ensino de Educação Física. São Paulo: Cortez, 1992.

SOLÉ, I.; COLL, C. Os professores e a concepção construtivista. In: COLL, C. et al. O construtivismo na sala de aula. São Paulo: Ática, 1999. p. 9-28.

TEDESCO, J. C. O novo pacto educativo. São Paulo: Ática, 1998.

TOGNETTA, L. R. P. A construção da solidariedade e a educação do sentimento na escola. Campinas: Mercado de Letras, 2007.

VINHA, T. P.; TOGNETTA, L. R. P. A construção da autonomia moral na escola: a intervenção nos conflitos interpessoais e a aprendizagem dos valores. Campinas: Mercado de Letras, 2003.

Recebido em: 04/04/2012

Revisado em: 08/10/2012

Aprovado em: 20/12/2012

Endereço para correspondência:

crepaldi@unoeste.br

Marcelo Crepaldi Leitão

Associação Prudentina de Educação e Cultura.

Rua José Bongiovani, 700

Jardim Bongiovani

19050-900 - Presidente Prudente, SP - Brasil 